\title{
ASSESSMENT OF THE ANTIOXIDANT PROPERTIES OF TOMATO EXTRACTS: A SYNERGISTIC APPROACH USING IN VITRO CHEMICAL TESTS AND CELL-BASED ASSAYS
}

\author{
F.J. García-Alonso*, I. Navarro-González, G. Ros and M.J. Periago \\ Department of Food Science and Nutrition, Faculty of Veterinary Science, Campus de Espinardo, 30.100 Murcia. \\ Spain Regional Campus of International Excellence "Campus Mare Nostrum"
}

(Received: 31 January 2014; accepted: 8 March 2014)

\begin{abstract}
The aim of this research was to assess the total antioxidant activity (TAA) of lipophilic $\left(\mathrm{L}_{\text {extr }}\right)$ and hydrophilic $\left(\mathrm{H}_{\text {extr }}\right)$ tomato extracts using in vitro chemical tests and cell-based assays, focusing on possible synergistic actions between tomato antioxidants. Both $\mathrm{H}_{\text {extr }}$ and $\mathrm{L}_{\text {extr }}$ were HPLC analysed for their carotenoids, phenolic compounds, and ascorbic acid contents. For the evaluation of TAA, extracts were assayed alone or in combination using in vitro chemical tests (TEAC, FRAP) and cell-based (CAA) assays using human hepatoma (HepG2) and human histiocytic lymphoma (U937) cells. The only carotenoid detected in $\mathrm{L}_{\text {extr }}$ was lycopene, while a mixture of phenolic compounds (chlorogenic acid, caffeic acid, and rutin) was identified in $\mathrm{H}_{\text {extr }}$. Ascorbic acid was not found either in $\mathrm{H}_{\text {extr }}$ or in $\mathrm{L}_{\text {extr }}$. Upon extract combination $(1: 1, \mathrm{v} / \mathrm{v})$, the FRAP assay revealed additive action between $\mathrm{L}_{\text {extr }}$ and $\mathrm{H}_{\text {extr }}$, whilst a slight synergistic action was observed in TAA as measured by the TEAC assay. Synergistic action was better revealed when TAA was analysed using either U937 or HepG2 cells. This could be explained by the presence of a multiphase media (cell membrane and extra- and intracellular media) that might facilitate the distribution and interaction of antioxidants with different polarities and different mechanisms of action.
\end{abstract}

Keywords: lycopene, phenolics, total antioxidant activity, cell cultures assay

Nutrition plays a role in the prevention of chronic diseases related to oxidative stress such as cancer, cardiovascular, neurodegenerative, or inflammatory diseases. Epidemiological studies have shown that regular consumption of plant-foods, which are natural sources of dietary antioxidants, is associated with reduced risk of such diseases (VETRANI et al., 2013). In this context, it has been proposed that the antioxidant potential of foods and diets may arise from additive and synergistic actions of the different antioxidant phytochemicals present in the food matrix (LiU, 2003; ZANFINI et al., 2010; WANG et al., 2011). Synergism is, in general, the phenomenon in which a number of compounds, when present together in the same system, have a more pronounced effect than that which would be derived from a simple additivity concept (LAGUERRE et al., 2007). Tomato is one of the most consumed vegetables in the world. In recent decades, its consumption has been associated with the prevention of several diseases mainly due to its content of antioxidants, including carotenes (lycopene as well as $\beta$-carotene), ascorbic acid, tocopherol, and phenolic compounds (Periago et al., 2009). Since tomatoes provide a variety of dietary lipo- and hydrophilic antioxidants, in the present study we assessed the antioxidant activity of lipo- and hydrophilic tomato extracts using in vitro chemical tests and cell-based assays, focusing on possible synergistic actions between extracts.

\footnotetext{
* To whom correspondence should be addressed Phone: +34-868-887985; fax: +34-868-884147; e-mail: fjgarcia@um.es
} 


\section{Materials and methods}

\subsection{Reagents and chemicals}

Minimum essential medium with Earle's salts (MEM), RPMI 1640 medium, N-2hydroxyethylpiperazine-N-2-ethane sulphonic acid (HEPES), penicillin, streptomycin, nonessential amino acids, pyruvate, and L-glutamine were purchased from Gibco (Paisley, Scotland, UK). Foetal bovine serum (FBS), 2',7'-dichlorofluorescin diacetate (DCFHDA), 3-(4,5-dimethyl thiazol-2-yl)-2,5-diphenyl tetrazolium bromide (MTT), 2,2'-azinobis(3ethylbenzothiazoline-6-sulphonate) (ABTS), 6-hydroxy-2,5,7,8-tetramethylchroman-2carboxylic acid (Trolox), tert-butylhydroperoxide $(t \mathrm{BOOH}) 70 \%$ solution in water were purchased from Sigma-Aldrich (St. Louis, USA). Lycopene standard was purchased from CaroteNature (Lupsingen, Switzerland), $\beta$-carotene and phenolic compound standards were purchased from Sigma (St. Louis, EE.UU), dimethylsulphoxide (DMSO) and L-(+)-ascorbic acid were purchased from Merck (Darmstadt, Germany) and 2,4,6-tripyridyl-s-triazine (TPTZ) was purchased from Fluka (Buchs, Switzerland). All other reagents were of the highest grade obtainable.

\subsection{Preparation of tomato extracts and analysis of bioactive compounds}

Tomato lipo- and hydrophilic extracts were prepared from a commercially available tomato concentrate. To obtain the lipophilic tomato extract $\left(\mathrm{L}_{\text {extr }}\right), 5 \mathrm{~g}$ tomato concentrate was extracted in a mixture of $250 \mathrm{ml}$ hexane and $20 \mathrm{ml}$ water for $30 \mathrm{~min}$ using a magnetic stirrer. The hexane upper layer was dried in a rotary evaporator and the resulting extract redissolved in $25 \mathrm{ml}$ DMSO. Similarly, the hydrophilic tomato extract $\left(\mathrm{H}_{\text {extr }}\right)$ was prepared by magnetic stirring of $5 \mathrm{~g}$ tomato concentrate in $250 \mathrm{ml}$ distilled water for $30 \mathrm{~min}$. The extract was filtered through Whatman paper No. 1 and concentrated in a rotary evaporator to $25 \mathrm{ml}$. Finally, the extracts were filtered through a $0.2 \mu \mathrm{m}$ pore size syringe filter (Millex, Millipore, Cork, Ireland) and stored at $-80{ }^{\circ} \mathrm{C}$ until analysed. For the assays, extracts were analysed diluted, undiluted, and combined (Table 1). The content of bioactive compounds in both $\mathrm{L}_{\text {extr }}$ and $\mathrm{H}_{\text {extr }}$ tomato extracts was analysed by HPLC. Carotenoids were analysed as described by BöHм (2001), phenolic compounds were analysed according to NAVARRO-GonZÁLEZ and coworkers (2011), and vitamin C was assayed by the method of Esteve and co-workers (1995).

\subsection{Analysis of total antioxidant activity (TAA)}

1.3.1. In vitro chemical TAA tests. Two common TAA tests were used in this study: the Trolox Equivalent Antioxidant Capacity (TEAC) assay (Miller et al., 1996) and the Ferric Reducing/ Antioxidant Power (FRAP) assay (Benzie \& Strain, 1996). Trolox in the range 0-125 $\mu \mathrm{M}$ (TEAC) and 0-250 $\mu \mathrm{M}$ (FRAP) was used for linear calibration $\left(\mathrm{R}^{2}=0.99\right)$.

1.3.2. Cell-based antioxidant activity (CAA) tests. The CAA assay is based on prevention of intracellular reactive oxygen species (ROS) production, which is detected using the nonfluorescent compound DCFHDA. In this method, the probe DCFHDA is taken up by cells and deacetylated to DCFH by intracellular esterases (WoLFE \& LiU, 2007). Free radicals generated from $\mathrm{tBOOH}$ lead to the oxidation of DCFH to fluorescent DCF, and the level of fluorescence measured upon excitation is proportional to the level of oxidation. Antioxidant compounds present in the samples quench free radicals and inhibit the generation of DCF. For the assay, tBOOH, a widely used model of in vitro oxidative stress (AlíA et al., 2005), was used as a free radical generator. 
Table 1. Carotenoid and phenolic content of tomato extracts* and their combinations $(\mu \mathrm{M})$.

\begin{tabular}{lccccc}
\hline Compound & $\begin{array}{c}\text { Lipophilic } \\
\text { extract } \\
\left(\mathrm{L}_{\text {extr }}\right)\end{array}$ & $\begin{array}{c}\text { Hydrophilic } \\
\text { extract } \\
\left(\mathrm{H}_{\text {extr }}\right)\end{array}$ & $\begin{array}{c}\text { Combined } \\
\text { extract } \\
\left(\mathrm{LH}_{\text {extr }}\right)\end{array}$ & $\begin{array}{c}\text { Diluted } \\
\text { lipophilic } \\
\text { extract } \\
\left(\mathrm{Ld}_{\text {extr }}\right)\end{array}$ & $\begin{array}{c}\text { Diluted } \\
\text { hydrophilic } \\
\text { extract } \\
\left(\mathrm{Hd}_{\text {extr }}\right)\end{array}$ \\
\hline Lycopene & $247.17 \pm 0.03$ & nd & 123.59 & 123.59 & nd \\
Total phenolics & nd & 48.83 & 24.42 & nd & 24.42 \\
Chlorogenic acid & & $35.48 \pm 0.02$ & 17.74 & & 17.74 \\
Caffeic acid & & $1.94 \pm 0.01$ & 0.97 & & 0.97 \\
Rutin & & $11.41 \pm 0.01$ & 5.71 & & 5.71 \\
\hline
\end{tabular}

*For the TAA and CAA assays, extracts were analysed diluted, undiluted, and combined as indicated as follows: $\mathrm{L}_{\text {extr }}$ and $\mathrm{H}_{\text {extr }}$ were assayed undiluted, $\mathrm{LH}_{\text {extr }}$ was obtained by mixing $50 \% \mathrm{~L}_{\text {extr }}$ and $50 \% \mathrm{H}_{\text {extr }}$ and then assayed; $\mathrm{Ld}_{\text {extr }}$ and $\mathrm{Hd}_{\text {extr }}$ were obtained by diluting 1:1 (v:v) in water before being assayed. For $\mathrm{L}_{\text {extr }}$ and $\mathrm{H}_{\text {extr }}$, results are expressed as mean $\pm \mathrm{SD}$. In $\mathrm{LH}_{\text {extr }}$ and $\mathrm{Ld}_{\text {extr }}$ and $\mathrm{Hd}_{\text {extr }}$ the amount of bioactive compounds was estimated according to the dilution applied $(1: 1 ; \mathrm{v} / \mathrm{v})$. Vitamin $\mathrm{C}$ was not detected. This could be explained by the fact that extracts were obtained from a tomato concentrate. Therefore, heating during the concentration process and further storage of the product may have degraded vitamin $\mathrm{C}$; nd: not detected

CAA using human histiocytic lymphoma (U937) cells: U937 cells (American Type Culture Collection, ATCC No. CLR-1593.2, Rockville, MD, USA) were cultured in suspension in RPMI 1640 medium supplemented with 10\% (v/v) FBS, 1\% non-essential amino acids, $1.5 \mathrm{~g} \cdot \mathrm{l}^{-1} \mathrm{NaHCO}_{3}, 1 \mathrm{mM}$ pyruvate, $10 \mathrm{mM}$ HEPES, $2 \mathrm{mM}$ L-glutamine, $4.5 \mathrm{~g} \cdot \mathrm{l}^{-1}$ glucose, $100 \mathrm{U} \cdot \mathrm{ml}^{-1}$ penicillin, and $100 \mathrm{mg} \cdot \mathrm{ml}^{-1}$ streptomycin, at $37{ }^{\circ} \mathrm{C}$ in a humidified atmosphere of $95 \%$ air $-5 \% \mathrm{CO}_{2}$. For the experiments, cells were washed with saline A buffer pH $7.3\left(8.812 \mathrm{~g} \cdot \mathrm{l}^{-1} \mathrm{NaCl}, 0.372 \mathrm{~g} \cdot \mathrm{l}^{-1} \mathrm{KCl}, 0.336 \mathrm{~g} \cdot \mathrm{l}^{-1} \mathrm{NaHCO}_{3}\right.$, and $0.9 \mathrm{~g} \cdot \mathrm{l}^{-1}$ glucose), adjusted to a density of $50000 \mathrm{cells} \cdot \mathrm{ml}^{-1}$ in saline A containing $12.5 \mu \mathrm{M}$ DCFHDA and incubated for $15 \mathrm{~min}$ at $37^{\circ} \mathrm{C}$. After that, aliquots of $2 \mathrm{ml}$ of the cell suspension were transferred into test tubes and Trolox or tomato extracts were added at the desired concentrations $10 \mathrm{~min}$ before exposure to $25 \mu \mathrm{M}$ tBOOH for $30 \mathrm{~min}$ at $37^{\circ} \mathrm{C}$. Fluorescence intensity was measured by flow cytometry (Cytomics FC 500, Beckman Coulter Inc., Fullerton, CA, USA). Trolox in the range $0-10 \mu \mathrm{M}$ was used for linear calibration $\left(\mathrm{R}^{2}=0.99\right)$. Cell viability was checked during flow cytometry analyses using propidium iodide staining. Tomato extracts were tested at $1 \%$ final concentration in the cultures. Under these conditions cell viability was always $>95 \%$.

CAA using human Caucasian hepatocyte carcinoma (HepG2) cells: HepG2 cells (European Collection of Cell Cultures; ECACC No. 85011430, CAMR, Salisbury, Wiltshire, $\mathrm{UK}$ ) were routinely grown in MEM supplemented with $10 \%(\mathrm{v} / \mathrm{v}) \mathrm{FBS}, 100 \mathrm{U} \cdot \mathrm{ml}^{-1}$ penicillin, $100 \mathrm{mg} \cdot \mathrm{ml}^{-1}$ streptomycin, $1 \%$ non-essential amino acids, and $2 \mathrm{mM} \mathrm{L}$-glutamine, in a humidified atmosphere of $95 \%$ air $-5 \% \mathrm{CO}_{2}$ at $37{ }^{\circ} \mathrm{C}$. For the experiments, cells were seeded onto 24-well plates at a density of 200000 cells per well and grown to confluence. On the treatment day, cells were preloaded with serum-free MEM containing 12.5 $\mu$ M DCFCDA for $15 \mathrm{~min}$. After that, media was replaced by serum-free MEM containing known concentrations of Trolox or tomato extracts $10 \mathrm{~min}$ before exposure to $250 \mu \mathrm{M} \mathrm{tBOOH}$ for $30 \mathrm{~min}$ at $37^{\circ} \mathrm{C}$. Fluorescence intensity was measured in a Fluostar Galaxy fluorimeter(BMG LabTechnologies, Offenburg, Germany). Trolox in the range $0-4 \mu \mathrm{M}$ was used for linear calibration $\left(\mathrm{R}^{2}=0.99\right)$. After the whole treatment process, cell viability was checked by the MTT assay (Mosmann, 
1983). Tomato extracts were tested at $0.2 \%$ final concentration in the culture media. Under these conditions cell viability was always $>95 \%$.

\subsection{Establishment of synergistic, additive, or antagonistic effects}

To study the antioxidant nature of extract combinations (synergistic, additive, or antagonistic), the theoretical TAA of the combined extract $\left(\mathrm{LH}_{\mathrm{t}}\right)$ was calculated as the following sum:

$$
{ }_{\text {TAA }} \mathrm{LH}_{\mathrm{t}}={ }_{\mathrm{TAA}} \mathrm{Ld}_{\text {extr }}+{ }_{\mathrm{TAA}} \mathrm{Hd}_{\text {extr }}
$$

Then, ${ }_{\text {TAA }} \mathrm{LH}_{\mathrm{t}}$ was compared to the experimentally measured TAA of the combined extract $\left({ }_{\mathrm{TAA}} \mathrm{LH}_{\text {extr }}\right)$ so that when:

\subsection{Statistics}

$$
\begin{gathered}
{ }_{\mathrm{TAA}} \mathrm{LH}_{\text {extr }}<{ }_{\mathrm{TAA}} \mathrm{LH}_{\mathrm{t}} \rightarrow \text { Antagonism } \\
{ }_{\mathrm{TAA}} \mathrm{LH}_{\text {extr }}={ }_{\text {TAA }} \mathrm{LH}_{\mathrm{t}} \rightarrow \text { Addition } \\
{ }_{\mathrm{TAA}} \mathrm{LH}_{\text {extr }}>{ }_{\mathrm{TAA}} \mathrm{LH}_{\mathrm{t}} \rightarrow \text { Synergy }
\end{gathered}
$$

Data were analysed by Statistical Package SPSS 15.0 version for Windows (SPSS Inc., Chicago, IL, USA). Comparisons between the means were analysed by one-way analysis of variance (ANOVA) followed by Tukey's test, considering a $\mathrm{P}$ value $<0.05$ statistically significant.

\section{Results and discussion}

As evidenced by Figure 1, an additive effect between lipo- and hydrophilic antioxidants was observed when TAA was measured by the FRAP assay $\left({ }_{T A A} \mathrm{LH}_{\text {extr }}{ }_{\text {TAA }}{ }^{2} \mathrm{LH}_{\mathrm{t}}\right)$ (Fig. 1A), while a slight synergistic action is observed when using the TEAC test $\left(_{\mathrm{TAA}} \mathrm{LH}_{\text {extr }}{ }_{\mathrm{TAA}} \mathrm{LH}_{\mathrm{t}}\right)$. This was revealed by a 0.9 -fold increase of ${ }_{\text {TAA }} \mathrm{LH}_{\text {extr }}$ with respect to ${ }_{\mathrm{TAA}} \mathrm{LH}_{\mathrm{t}}$ showing significant differences in a pair-wise comparison (Fig. 1B). Stronger synergistic effects were observed when tomato extracts were tested in cell-based assays, as 1.5 -fold and 5-fold increases of ${ }_{\text {TAA }} \mathrm{LH}_{\text {extr }}$ with respect to ${ }_{\text {TAA }} \mathrm{LH}_{\mathrm{t}}$ were observed in HepG2 and U937 cells, respectively (Figs $1 \mathrm{C}$ and $1 \mathrm{D})$.

Cooperative effects between antioxidants and plant-food extracts have been previously reported in different chemical systems. In a recent study of major antioxidants and antioxidant activity in eight tomato cultivars, hydrophilic antioxidant activity determined by the ABTS assay had far more significant impact (83\%) on total antioxidant activity. The analysis of twocomponent mixtures showed significant synergism between lycopene-lutein, lycopene-betacarotene, and alpha-tocopherol-beta-carotene. However, ascorbic acid proved to be the most efficient antioxidant (KoTíKová et al., 2011).

However, to our knowledge, studies using cell-based assays to assess synergistic action between antioxidants are still not commonly used (MuraKAMI et al., 2003; BlaSA et al., 2011). Cell-based assays are considered to provide a more biologically relevant protocol to measure TAA than chemical tests, as they address issues of uptake, distribution, and metabolism. Furthermore, cell models allow the use of relatively low concentrations of oxidant and avoidance of using excessive levels of antioxidants (WoLfe \& Liv, 2007). It should be noted that, in our study, the final concentrations in the cultures were in the range c.a. $0.25-2.5 \mu \mathrm{M}$ for lycopene and c.a. $0.05-0.5 \mu \mathrm{M}$ for total phenolics. Such concentrations are physiologically attainable under a usual diet (MANACH et al., 2004; JACOB et al., 2008). 
A

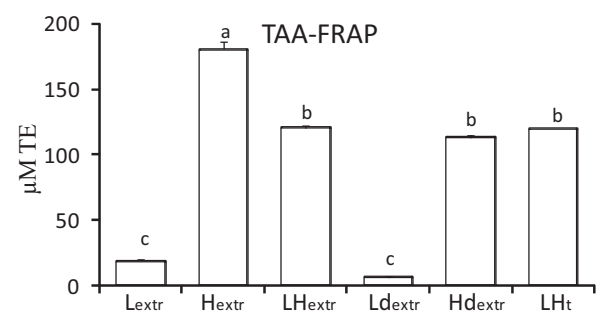

C

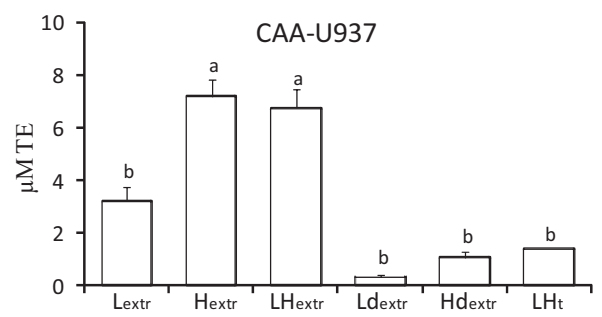

B

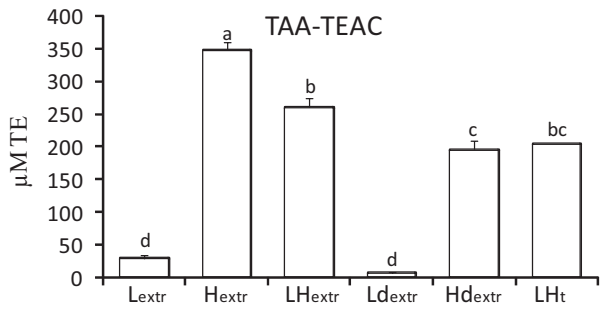

D

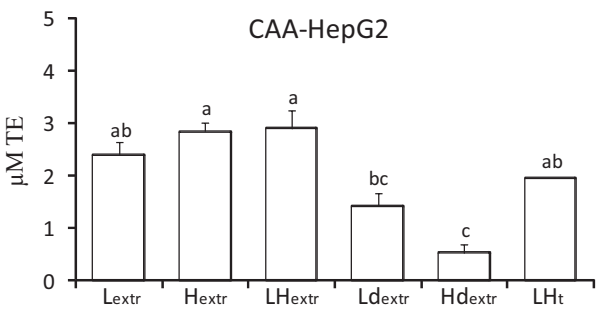

Fig. 1. Total antioxidant activities of tomato extracts and their combinations as measured by in vitro chemical tests and cell-based assays. Results (mean \pm SEM of at least three separate experiments) are expressed as $\mu \mathrm{M}$ Trolox Equivalentes (TE). Lipophilic extract $\left(\mathrm{L}_{\text {extr }}\right)$, hydrophilic extract $\left(\mathrm{H}_{\text {extr }}\right)$, combined extract $\left(\mathrm{LH}_{\text {extr }}\right)$, diluted lipophilic extract $\left(\mathrm{Ld}_{\text {extr }}\right)$, diluted hydrophilic extract $\left(\mathrm{Hd}_{\text {extr }}\right)$, theoretical total antioxidant activity of the combined extract ( $\mathrm{LH}_{t}$ ). (A) TAA-FRAP; total antioxidant activity measured by the FRAP assay. (B) TAA-TEAC; total antioxidant activity measured by the TEAC assay. (C) CAA-U937; cell-based antioxidant activity measured using U937 cells. (D) CAA-HepG2: cell-based antioxidant activity measured using HepG2 cells. Different superscript letters mean statistical significance $(\mathrm{P}<0.05)$

Synergism between antioxidants may arise via different mechanisms: (i) via regeneration reactions, (ii) via sacrificial oxidation (where one antioxidant, by radical scavenging, protects the other one) or (iii) by exertion of different mechanisms of action (singlet oxygen quenchers and chain-breaking antioxidants, metal chelators), thus prolonging the antioxidative effect of each other. Also, in multiphase media, the interaction of antioxidants with different polarities, which are thus distributed in different phases or solvents, could induce synergy (e.g. ascorbate-induced regeneration of $\alpha$-tocopherol) (LAGUERRE et al., 2007). In line with this, the synergistic action observed in cell-based assays could rely on the presence of a multiphase media (cell membrane and extra- and intracellular media) that might facilitate the distribution and interaction of lycopene and phenolics in preventing oxidation by means of different antioxidant mechanisms (e.g. radical scavenging, metal chelation).

The contribution of $\mathrm{L}_{\text {extr }}$ to TAA measured in cell systems could be explained by the affinity of carotenoids for lipid compartments together with the characteristics of the cellbased assays. The organic hyperoxide $\mathrm{tBOOH}$, used herein as oxidative stressor, decomposes to other alkoxyl and peroxyl radicals in a reaction aided by metal ions that leads to damage in lipophilic cell compartments (Alía et al., 2005). Acting as chain-breaking antioxidants, carotenoids have been shown to be capable of inhibiting free radical reactions involving species such as peroxyl radicals, therefore playing an important role in the protection of cellular membranes and lipoproteins against oxidative damage (SIES \& STAHL, 1995). 
Phenolics can exert antioxidant activity mainly by either free-radical scavenging or metal chelation (GArcía-Alonso et al., 2007; LAGUerre et al., 2007). In this manner, the phenolic compounds contained in the $\mathrm{H}_{\text {extr }}$ may have displayed antioxidant activity by protecting cell membranes from internal and/or external oxidation via scavenging of $t \mathrm{BOOH}-$ derived peroxyl radicals and/or by inhibiting the generation of further free radicals by Fentontype reactions. Interaction of polar phenolics with inner or outer cell membranes by hydrogen bonding has been suggested as playing a role in antioxidant protection (WoLFE \& LiU, 2007).

\section{Conclusions}

We herein report synergistic action between the carotenoid (lycopene) and hydrophilic phenolic fractions of tomato. Synergism is better revealed when using cell-based assays, which are considered more physiologically relevant than the commonly used chemical tests.

The authors thank the MINECO (Spain)/FEDER-EU Project BIO2012-38103 and the "Fundación Séneca" of CARM project 12031/P/09. The authors also wish to thank the staff of the Tissue Culture Unit of the Research Support Service of the University of Murcia.

\section{References}

Alía, M., Ramos, S., Mateos, R., Bravo, L. \& Goya, L. (2005): Response of the antioxidant defense system to tertbutyl hydroperoxide and hydrogen peroxide in a human hepatoma cell line (HepG2). J. Biochem. Mol. Toxicol., 19, 119-128.

Benzie, I.F.F. \& Strain, J.J. (1996): The ferric reducing ability of plasma (FRAP) as a measure of antioxidant power: The FRAP assay. Anal. Biochem., 239, 70-76.

Blasa, M., Angelino, D., Gennari, L. \& Ninfali, P. (2011): The cellular antioxidant activity in red blood cells (CAARBC): A new approach to bioavailability and synergy of phytochemicals and botanical extracts. Food Chem., $125,685-691$.

Вӧнм V. (2001): Use of column temperature to optimise carotenoid isomer separation by C30 high performance liquid chromatography. J. Sep. Sci., 24, 955-959.

Esteve, M.J., Farré, R., Frijola, A., López, J.C., Romera, J.M., Ramírez, M. \& Gil, A. (1995): Comparison of voltammetric and high performance liquid chromatographic methods for ascorbic acid determination in infant formulas. Food Chem., 52, 99-102.

García-Alonso, F.J., Guidarelli, A. \& Periago, M.J. (2007): Phenolic-rich juice prevents DNA single-strand breakage and cytotoxicity caused by tert-butylhydroperoxide in U937 cells: the role of iron chelation. J. Nutr. Biochem., 18, 457-466.

Jacob, K., Periago, M.J., Böhm, V. \& Ros-Berruezo, G. (2008): Influence of lycopene and vitamin C from tomato juice on biomarkers of oxidative stress and inflammation. Br. J. Nutr., 99, 137-146.

Kotíková, Z., Lachman, J., Hejtmánková, A. \& Hejtmánková, K. (2011): Determination of antioxidant activity and antioxidant content in tomato varieties and evaluation of mutual interactions between antioxidants. LWT Food Sci. Technol., 44, 1703-1710.

Laguerre, M., Lecomte, J. \& Villeneuve, P. (2007): Evaluation of the ability of antioxidants to counteract lipid oxidation: Existing methods, new trends and challenges. Prog. Lipid Res., 46, 244-282.

LiU, R.H. (2003): Health benefits of fruit and vegetables are from additive and synergistic combinations of phytochemicals. Am. J. Clin. Nutr., 78, 517-520.

Manach, C., Williamson, G., Morand, C., Scalbert, A. \& Remesy, C. (2004): Bioavailability and bioefficacy of polyphenols in humans. I. Review of 97 bioavailability studies. Am. J. Clin. Nutr., 81, 230-242.

Miller, N.J., Sampson. J., Candeias, L.P., Bramley, P.M. \& Rice-Evans, C.A. (1996): Antioxidant activities of carotenes and xanthophylls. FEBS Lett., 384, 240-242.

Acta Alimentaria 44, 2015 
Mosmann, T. (1983): Rapid colorimetric assay for cellular growth and survival: Application to proliferation and citotoxicity assays. J. Inmunol. Methods, 65, 55-63.

Murakami, A., Takahashi, D., Koshimizu, K. \& Ohigashi, H. (2003): Synergistic suppression of superoxide and nitric oxide generation from inflammatory cells by combined food factors. Mutat. Res., 523-524, 151-161.

Navarro-González, I., García-Valverde, V., García-Alonso, J. \& Periago, M.J. (2011): Chemical profile, functional and antioxidant properties of tomato peel fiber. Food Res. Int., 44, 1528-1535.

Periago, M.J., Garcia-Alonso, F.J., Jacob, K., Olivares, A.B., Bernal, M.J., Iniesta, M.D., Martinez, C. \& Ros, G. (2009): Bioactive compounds, folates and antioxidant properties of tomatoes (Lycopersicum esculentum) during vine ripening. Int. J. Food Sci. Nutr., 60, 694-670.

Sies, H. \& Stahl, W. (1995): Vitamins E and C, beta-carotene, and other carotenoids as antioxidants. Am. J. Clin. Nutr., 62, 1315-1321.

Vetrani, C., Costabile, G., Di Marino, L. \& Rivellese, A.A. (2013): Nutrition and oxidative stress: a systematic review of human studies. Int. J. Food Sci. Nutr., 64, 312-326.

Wang, M., Meckling, K.A., Marcone, M.F., Kakuda, Y. \& Tsao, R. (2011): Synergistic, additive, and antagonistic effects of food mixtures on total antioxidant capacities. J. Agr. Food Chem., 5, 960-968.

Wolfe, K.L. \& Liu, R.U. (2007): Cellular antioxidant activity (CAA) assay for assessing antioxidants, foods and dietary supplements. J. Agr. Food Chem., 55, 8896-8907.

Zanfini, A., Corbini, G., La Rosa, C. \& Dreassi, E. (2010): Antioxidant activity of tomato lipophilic extracts and interactions between carotenoids and $\alpha$-tocopherol in synthetic mixtures. LWT - Food Sci. Technol., 43, $67-72$. 